\title{
Risk factors and reporting status for attempted Suicide: A hospital-based study
}

\section{Punithakumary \\ Purushothaman, Kariyarath Cheriyath Premarajan ${ }^{1}$, Swaroop Kumar Sahu', Shivanand Kattimani ${ }^{2}$}

Department of Community Medicine, PSG Institute of Medical Science and Research, Coimbatore, Tamil Nadu,

${ }^{1}$ Departments of Preventive and Social Medicine and ${ }^{2}$ Psychiatry, Jawaharlal Institute of Postgraduate Medical Education \&

Research, Puducherry, India

Address for the Correspondence:

Dr. P. Punithakumary Department of Community Medicine, PSG Institute of Medical Science and Research, Coimbatore, Tamil Nadu, India.

E-mail: punithakumary.p@ gmail.com

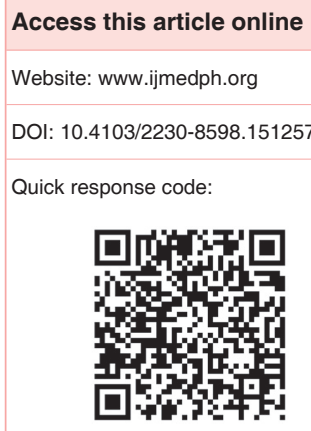

Context: Suicide is a major public health problem and ranks second among the leading causes of death in both genders in 15-34 years. Suicidal attempts are 20 times higher than the completed suicides. Aims: The aim was to identify background risk factors and precipitating factors for suicide attempts in Pondicherry district and to find out the reporting status of suicide attempts. Settings and Design: Hospital-based descriptive study. Subjects and Methods: 200 subjects who have attempted suicide from JIPMER and Indira Gandhi Government Hospital and Post Graduate Institute Pondicherry were interviewed. Monthly data on attempted suicide were collected from Crime Record Bureau of Pondicherry and Villupuram district and Medical Records Department of these two hospitals was collected. Statistical Analysis Used: SPSS version 16.0 was used. Chi-square test was used to test the significance of the difference between two proportions. Results: Most common precipitating factor found among those who attempted suicide was verbal abuse, most often by parents $(31.9 \%)$. The most common mode of suicide attempt was consumption of chemical poison in $56 \%$ of subjects followed by plant poison $41.5 \%$. The suicide intention was high in $81.5 \%$ of subjects. No significant difference in risk factors could be found between subjects from Pondicherry and villupuram district. It was found that there was gross under-reporting of attempted suicides to Crime Records Bureau. Conclusions: Measurement of suicide intention enables us to predict the future suicidal behavior in adults; individuals with a high suicide intent index pose a major public health problem. Hence, there is a need for opportunistic screening of those with suicidal ideations as well as counseling and follow-up of those with suicide attempts to prevent further attempts.

Key words: Poisoning, Pondicherry, suicide attempt, suicide intention, suicides, Tamil Nadu

\section{INTRODUCTION}

Suicide is a major public health problem and a leading cause of death worldwide. Every year, approximately 1 million people commit suicide. ${ }^{[1]}$ Suicide ranks second among the leading causes of death for both genders in the age group of 15-34 years. This represents a massive loss of young,

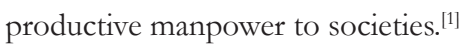

Globally, there is an increasing trend of a suicide rate from 10 per lakh population in 1950 to 18 per lakh in 1999. ${ }^{[2]}$ In India, there is an increasing trend from 10.4 per lakh in 2003 to 10.9 per lakh in 2009. In 2009, the suicide rate in Tamil Nadu was 21.5 per lakh which is twice the National level. Pondicherry recorded the highest suicide rate of 47.2 per lakh population in 2009; which is 4 times the national rate. ${ }^{[3,4]}$ Even though Pondicherry and Tamil Nadu are neighboring states, the reason for the wide disparity in the reported rates is not known.

Suicidal attempts are 20 times higher than the completed suicides. ${ }^{[1]}$ Globally, the estimated suicidal attempts per year was 9-36 million. ${ }^{[5]}$ There is one suicide attempt for every $3 \mathrm{~s}$ in the world. ${ }^{[1]}$ In India, prevalence and incidence of suicide attempts are $0.8 \%$ and $5.36 \%$ respectively. ${ }^{[6,7]}$ For each suicide, there are 7-10 suicide attempts. The attempted suicide is recognized as one of the important predictor of suicidal deaths. ${ }^{[8,9]}$

The complete burden of suicide attempts was highly underestimated because of the associated social stigma. Since the suicide is legally punishable crime in India (IPC 306), there is a threat of under- 
reporting. Many deaths, particularly in rural areas, are not registered due to inefficient registration system ${ }^{[10]}$ and also the fear of social and legal consequences associated with suicide.

This study was planned with the objective to identify background risk factors and precipitating factors for suicidal attempts, to find the difference, if any, in the risk factors among suicidal attempters from Pondicherry and Villupuram district and to find out the reporting status of suicide attempts in Pondicherry and Villupuram district.

\section{SUBJECTS AND METHODS}

With the approval of the institute ethics committee, this study was carried out in Pondicherry region of Union Territory of Puducherry and Villupuram district, from Tamil Nadu during 2009-2010. The population of Pondicherry and Villupuram were 9, 50,289 and $34,58,873$, respectively. ${ }^{[29,34]}$

A nonprobability sampling technique was adopted based on feasibility. To minimize selection bias, the first 8-10 patients admitted with suicide attempt (who satisfy eligibility criteria) in both JIPMER and Indira Gandhi Government Hospital and Post Graduate Institute (IGGHPGI) was selected. Some months had fewer patients, and they were compensated by recruiting additional patients in the subsequent months. It was decided that 200 subjects with suicide attempts would be interviewed within a period of 1-year.

The data on suicidal attempts were collected from three sources:

1. Subjects who attempted suicide and admitted in JIPMER and IGGHPGI in Pondicherry;

2. Medical record department of the above-mentioned hospitals;

3. Crime Record Bureau (CRB) of Pondicherry and Villupuram district.

One hundred subjects each from JIPMER and IGGHPGI, who were admitted for their suicidal attempts were interviewed using pretested, semi-structured questionnaire. JIPMER, a central autonomous institute of national importance and IGGHPGI, a state government district hospital, were the two multispecialty hospitals in Pondicherry catering to all major ailments in Pondicherry and to several neighboring districts of Pondicherry like Villupuram, Cuddalore, Thiruvannamalai etc. For the purpose of present study, suicide attempt was defined as "A person who had made deliberate act of self-harm consciously aimed at self-destruction irrespective of his or her intention to die, with nonfatal outcome."'[11] After obtaining informed consent, information on the demographic profile, socioeconomic status, Bio-psychosocial detail, and precipitating factors were collected. Precipitating factor was defined as those provoking elements which elicited the current suicide attempt. Presumptive stressful life events scale ${ }^{[31]}$ and suicide intent scale ${ }^{[30]}$ were used to assess the presence of stress in their life in last 1-year period and intention to die. General health questionnaire ${ }^{[32]}$ was used to assess the presence of any psychological problem in the past 1-month and CAGE questionnaire ${ }^{[33]}$ was used to find problematic alcohol use.
Every month, the data on suicide attempt were collected from CRB of Pondicherry from December 2009 to November 2010. As the $\mathrm{CRB}$ of Villupuram district does not record data on attempted suicide, it could not be collected. Data on reported cases of suicide attempt from Pondicherry and Villupuram district were collected from Medical Records Department (MRD) of JIPMER and IGGHPGI every month. Data were analyzed using SPSS version 19: IBM. Chi-square test was used to test the significance of the difference between two proportions.

\section{RESULTS}

\section{Sociodemographic factors}

Among the study subjects $(n=200)$, more than half were in the age group of 20-29 years, mean age of suicide attempt was 26 \pm 9.1 years (mean \pm standard deviation [SD]). Female subjects comprised about $65 \%$ of the study sample. Majority (62\%) was in lower socioeconomic status, and $69.5 \%$ were from the rural area. The other baseline sociodemographic characteristics are found in Table 1.

\section{Biopsychosocial factors}

Contributing factors for suicide attempt identified were history of chronic illness (16.5\%), family history of suicide or suicide attempt $(12.5 \%)$, past history of suicide attempt $(7 \%)$, and psychiatric illness $(1.3 \%)$. For $>62 \%$ of subjects who attempted suicides, there were no contributing factors. Among 70 males who attempted suicides, smoking was present in $22(31.4 \%)$ and problematic alcohol use was present in $32(45.7 \%)$.

\section{Precipitating factors}

The most common precipitating factor was verbal abuse $72(36 \%)$. Of the verbal abuse, $40(55.6 \%)$ was by parents, $23(31.9 \%)$ by spouse, $2(2.8 \%)$ by teacher, and $7(9.7 \%)$ by others. Illness referred to some physically and mentally disabling symptoms such as dysmenorrhea, headache, toothache, diabetes mellitus, sleeplessness, and heart disease among females and abdominal pain, headache, and tremor in hand were among males [Table 2].

The suicide intention was high in $163(81.5 \%)$ subjects and the mean suicide intention score was $12.8(\mathrm{SD}=3.19)$ [Table 3]. Psychological problem was present in 120 (60\%), and there was at least one stressful life events in $74(37 \%)$ subjects. The most common stressful life event was family conflict $26(13 \%)$ followed by large/heavy debt $22(11 \%)$. The most common mode of suicide attempt was by consumption of poison. Chemical poison was consumed by 112 $(56 \%)$ subjects [Table 4].

The risk factors for suicide attempts among the subjects from Pondicherry and Villupuram district were not found to be significantly different. Except, the subjects from Villupuram district were predominantly from the rural area $(95 \%)$ whereas more than half $(56 \%)$ of the subjects from Pondicherry were from the urban area. Seventy-two percent of them from Pondicherry were in class IV and V socioeconomic status. 


\begin{tabular}{|c|c|c|c|c|c|}
\hline \multirow{2}{*}{$\begin{array}{l}\text { Sociodemographic } \\
\text { details }\end{array}$} & \multicolumn{2}{|c|}{ Pondicherry Villupuram } & \multicolumn{2}{|c|}{ Total } & \multirow[t]{2}{*}{$P$} \\
\hline & $n_{1}=100$ & $n_{2}=100$ & $n=\mathbf{2 0 0}$ & $\%$ & \\
\hline \multicolumn{6}{|l|}{ Age in years } \\
\hline $10-19$ & 19 & 25 & 44 & 22.0 & \multirow{4}{*}{0.578} \\
\hline $20-29$ & 51 & 52 & 103 & 51.5 & \\
\hline $30-39$ & 19 & 16 & 35 & 17.5 & \\
\hline$\geq 40$ & 11 & 7 & 18 & 9 & \\
\hline \multicolumn{6}{|l|}{ Gender } \\
\hline Male & 28 & 42 & 70 & 35.0 & \multirow{2}{*}{0.038} \\
\hline Female & 72 & 58 & 130 & 65.0 & \\
\hline \multicolumn{6}{|l|}{ Domicile } \\
\hline Urban & 56 & 5 & 61 & 30.5 & \multirow{2}{*}{$<0.001$} \\
\hline Rural & 44 & 95 & 139 & 69.5 & \\
\hline \multicolumn{6}{|l|}{ Religion } \\
\hline Hindu & 97 & 97 & 194 & 97.0 & \multirow{3}{*}{0.717} \\
\hline Christian & 2 & 1 & 3 & 1.5 & \\
\hline Muslim & 1 & 0 & 1 & 0.5 & \\
\hline \multicolumn{6}{|l|}{ Type of house } \\
\hline Kutcha & 34 & 51 & 85 & 42.5 & \multirow{3}{*}{$<0.001$} \\
\hline Semipucca & 19 & 28 & 47 & 23.0 & \\
\hline Pucca & 47 & 21 & 68 & 34.5 & \\
\hline \multicolumn{6}{|l|}{ Education } \\
\hline Never attended & 22 & 18 & 40 & 20.0 & \multirow{4}{*}{0.171} \\
\hline Primary & 31 & 32 & 63 & 31.5 & \\
\hline Secondary & 31 & 42 & 73 & 36.5 & \\
\hline College & 16 & 8 & 24 & 12.0 & \\
\hline \multicolumn{6}{|l|}{ Occupation } \\
\hline Non workers & 51 & 44 & 95 & 47.5 & \multirow[t]{6}{*}{0.220} \\
\hline Homemaker & 21 & 5 & 26 & & \\
\hline Students & 10 & 16 & 26 & & \\
\hline Unemployed & 21 & 23 & 44 & & \\
\hline Skill I & 40 & 52 & 92 & 46.0 & \\
\hline Skill II and III & 9 & 4 & 13 & 6.5 & \\
\hline \multicolumn{6}{|c|}{ Socioeconomic status* } \\
\hline I, II and III & 28 & 48 & 76 & 38.0 & \multirow{2}{*}{0.004} \\
\hline IV and V & 72 & 52 & 124 & 62.0 & \\
\hline \multicolumn{6}{|l|}{ Type of family } \\
\hline Nuclear & 75 & 63 & 138 & 69.0 & \multirow{2}{*}{0.067} \\
\hline Joint & 25 & 37 & 62 & 31.0 & \\
\hline \multicolumn{6}{|l|}{ Marital status } \\
\hline Unmarried & 40 & 49 & 89 & 44.5 & \multirow{3}{*}{0.281} \\
\hline Married & 55 & 49 & 104 & 52.0 & \\
\hline $\begin{array}{l}\text { Separated and } \\
\text { widowed }\end{array}$ & 5 & 2 & 7 & 3.5 & \\
\hline
\end{tabular}

\section{Reporting status of attempted suicide}

During the 1-year study period, CRB of Pondicherry reported 170 cases of suicide attempt. MRD of both hospitals reported suicide attempt from Pondicherry and Villupuram as 1129 cases and 506 cases, respectively. The rate of suicide attempts as per CRB Pondicherry was 17.88 per lakh population. The estimated suicidal attempt rate as per data collected from MRD was 118.80 and 14.6 per lakh population for Pondicherry and Villupuram district, respectively. There is gross underreporting of suicide attempt cases to CRB Pondicherry [Figure 1].

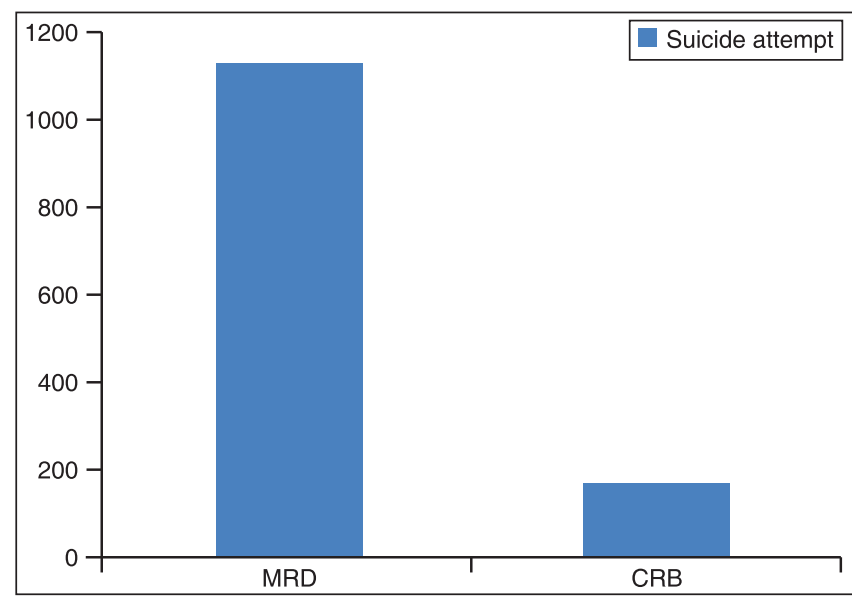

Figure 1: Under reporting of suicide attempt to CRB Pondicherry in 1 year period (2009-2010)

\section{DISCUSSION}

The commonest risk factors identified were age 20-29, female gender, rural domicile, low socioeconomic status. The most common precipitating factor was verbal abuse. These findings were in comparison with other studies. ${ }^{[8,12,13,19,20]}$ Rate of suicide attempts as per CRB Pondicherry was 17.88 . The estimated suicidal attempt rate as per data collected from MRD was 118.80 and 14.6 for Pondicherry and Villupuram district, respectively.

Majority of the subjects who attempted suicide were in age group of 20-29 years. Young people are more impulsive and less experienced with critical life situations and opt suicide attempt to tide over trivial issues. ${ }^{[14,15]}$ In accordance with other studies, ${ }^{[8,12,13]}$ it was observed in the study that the verbal abuse was the common reason for suicide attempt and younger people were more sensitive and easily get offended by criticism even from their own parent or spouse. Similar to many other studies, rural community and lower socioeconomic were more vulnerable compared to their counterparts. ${ }^{[19,20]}$ The possible reason for suicidal attempts among females could be due their sensitivity towards verbal abuse. Because they are traditionally viewed as weaker and inferior gender, any abuse has a negative impact on their self-esteem. ${ }^{[24,25]}$ Adolescent friendly school initiative emphasizing life skill development is highly recommended to enhance their abilities for adoptive and positive behavior. Such behavior change enables individuals to deal effectively with the demands and challenges of everyday life.

The history of suicide attempt was present in 7\%. Chandrasekaran ${ }^{[22]}$ found repetition rate of suicide attempt within 2 years of their previous attempt was $23 \%$. He also reported that repeaters had a higher level of suicidal intent. This shows that there is a need for strengthening the counseling services for attempted suicide cases and their families in hospital to prevent further attempts. This could be achieved by strengthening suicide prevention and follow-up clinic initiative. As compared to feasibility of detecting people at risk in the community and providing counseling, it is relatively easy to prevent further attempts by concentrating on those who get admitted with a history of suicidal attempts. Repetition rate of suicide ${ }^{[22]}$ was another 


\begin{tabular}{|c|c|c|c|c|}
\hline \multirow[t]{2}{*}{ Factors } & \multicolumn{2}{|c|}{ Pondicherry Villupuram } & \multicolumn{2}{|c|}{ Total } \\
\hline & $n$ & $n$ & $n$ & $\%$ \\
\hline Verbal abuse & 35 & 37 & 72 & 36.0 \\
\hline $\begin{array}{l}\text { Illness - intractable symptoms } \\
\text { like abdominal pain, headache }\end{array}$ & 23 & 19 & 42 & 21.0 \\
\hline Marital conflict & 14 & 11 & 25 & 12.5 \\
\hline Family related problem & 14 & 11 & 25 & 12.5 \\
\hline Interpersonal conflicts & 4 & 2 & 6 & 3.0 \\
\hline Physical abuse & 3 & 1 & 4 & 2.0 \\
\hline $\begin{array}{l}\text { Others - academic failure, loss } \\
\text { of hope in life, stress in working } \\
\text { place, love affair, death/neglect } \\
\text { of a spouse, influence of alcohol }\end{array}$ & 7 & 19 & 26 & 13.0 \\
\hline Total & 100 & 100 & 200 & 100 \\
\hline
\end{tabular}

\begin{tabular}{|c|c|c|c|c|}
\hline \multirow[t]{2}{*}{ Intention to die } & \multirow{2}{*}{$\frac{\text { Pondicherry }}{n}$} & \multirow{2}{*}{$\frac{\text { Villupuram }}{n}$} & \multicolumn{2}{|c|}{ Total } \\
\hline & & & $n$ & $\%$ \\
\hline High ( $(\geq 11)$ & 81 & 82 & 163 & 81.5 \\
\hline Medium (4-10) & 18 & 15 & 33 & 16.5 \\
\hline Low (0-3) & 1 & 3 & 4 & 2.0 \\
\hline Total & 100 & 100 & 200 & 100 \\
\hline
\end{tabular}

\begin{tabular}{|c|c|c|c|c|}
\hline \multirow[t]{2}{*}{ Mode of attempt } & \multirow{2}{*}{$\frac{\text { Pondicherry }}{n}$} & \multirow{2}{*}{$\frac{\text { Villupuram }}{n}$} & \multicolumn{2}{|c|}{ Total } \\
\hline & & & $n$ & $\%$ \\
\hline Chemical poisoning & 65 & 47 & 112 & 56 \\
\hline Plant poisoning & 33 & 50 & 83 & 41.5 \\
\hline Physical method & 2 & 3 & 5 & 2.5 \\
\hline Total & 100 & 100 & 200 & 100 \\
\hline
\end{tabular}

Chemical poisoning = Organo phosphorus, ant killer, rat killer, drug overdose, engine oil, bleaching powder, ala, baygon, anti-termite, floor cleaner, Plant poisoning

=Yellow oleander, abrus, oduvanthalai, tuber, Physical method = Hanging

important factor which needs to be addressed at the health system itself. Counseling the subjects admitted in the hospital for suicidal attempts need to be strengthened, and that will be one of the cost effective measures of identifying people at risk and intervention. ${ }^{[23]}$

The most common mode of suicide attempt was poisoning ${ }^{[12,16,21,24]}$ by chemicals, and it was a drug overdose ${ }^{[17]}$ for females. Women from rural area attempt suicide by plant poisons such as Yellow Oleander and Abrusprecatorious. These are cardiotoxic when ingested. Rural women belonging to low socioeconomic status are at risk for naturally available plant poisons whereas women from urban areas are at risk for drug overdose, because of easy availability and accessibility. ${ }^{[18]}$ The most common mode of suicide attempt was poisoning by chemicals because these insecticides were stored in their houses itself. Hence, there is a need for storing insecticides in a common place in villages, as done in Cuddalore district, (Tamil $\mathrm{Nadu}$ ) instead of houses. This could be a better intervention to prevent suicidal attempts.
Eighty-one percent $(n=163)$ of study subjects had high suicide intention. As a suicide intent index was a good predictor of future suicidal behavior in adults, individuals with a high suicide intent index pose a major public health problem. ${ }^{[26]}$

Though 37\% subjects had at least one stressful life events, it was the immediate precipitating factor which was significantly associated with high suicide intention and resulted in a suicide attempt. This was obvious in most of the study subjects who had stressful life events like extramarital relation of spouse, excessive alcohol abuse by a family member, infertility, marital conflict, family conflict, and conflict with in-laws. This study emphasizes the importance of life skill development at school level and continuous counseling opportunity to the vulnerable population.

Psychological distress was present in $65.5 \%$ study subjects. Several studies $^{[27,28]}$ have found that suicidal behavior was associated with psychological distress, and they are 9.5 times more prone for suicidal behavior compared to normal individuals.

The rate of attempted suicide was 17.9 per lakh population as per CRB for Pondicherry. However, data from MRD of JIPMER and GH Pondicherry alone showed the rate of Suicide attempt to be 118.8 per lakh population for Pondicherry. This revealed that there was gross under-reporting of cases of attempted suicide to the CRB Pondicherry. A possible reason could be due to the social stigma associated with the suicidal attempts and fear of legal implications; people prefer the private health facility than the government. Public-private partnership has to be strengthened to fill the gap in the reporting and counseling service delivery.

\section{RECOMMENDATIONS AND CONCLUSION}

Suicide attempt continues to be a major public health problem with a huge potential for preventive interventions. There is a need for follow-up of persons who had attempted suicide and their family members in order to prevent future attempts. As a preventive strategy, life skill training and problem-solving techniques may be regularly taught at schools to improve coping skills. Health education and public health measures for Judicial storing of potentially poisonous drugs and chemicals would help in reducing suicidal attempts by restricting access. Alleviation of the stigma and fear associated with legal punishments might result in better reporting of suicides. Therefore, there is an imminent need for certain modification in IPC 306 (suicide) and 309 (suicide attempt) is needed to make it more public friendly so that under-reporting could be minimized.

\section{REFERENCES}

1. World Health Organization. World Health Report. Mental Health - New Understanding-New Hope. Geneva: WHO; 2001.

2. WHO. Suicide Prevention: Emerging from Darkness. Facts and Figures. Mental Health and Substance Abuse. 2006. [internet]. Available from: http://www.searo.who.int/en/Section1174/Section1199/Section1567/ Section1824_8081.htm.

3. Crime in India 2009. National Crime Record Bureaue. Ministry of home affaires. Govt of India. East block-7, R.K Puram, New Delhi. 
4. Suicides in India, Chapter 2 [internet]. Available from: http://ncrb.gov.in/ ADSI2010/Suicides-10.pdf.

5. Bertolote JM, Fleischmann A, Butchart A, Besbelli N. Suicide, suicide attempts and pesticides: A major hidden public health problem. Bull Word Health Organ 2006;84:840.

6. Maselko J, Patel V. Why women attempt suicide: The role of mental illness and social disadvantage in a community cohort study in India. J Epidemiol Community Health 2008;62:817-22.

7. Das PP, Grover S, Avasthi A, Chakrabarti S, Malhotra S, Kumar S. Intentional self-harm seen in psychiatric referrals in a tertiary care hospital. Indian J Psychiatry 2008;50:187-91.

8. Chowdhury AN, Banerjee S, Brahma A, Das S, Sarker P, Biswas MK, et al. A prospective study of suicidal behaviour in Sundarban Delta, West Bengal, India. Natl Med J India 2010;23:201-5.

9. Chandrasekaran R, Gnanaseelan J, Sahai A, Swaminathan RP, Perme B. Psychiatric and personality disorders in survivors following their first suicide attempt. Indian J Psychiatry 2003;45:45-8.

10. Bose A, Konradsen F, John J, Suganthy P, Muliyil J, Abraham S. Mortality rate and years of life lost from unintentional injury and suicide in South India. Trop Med Int Health 2006;11:1553-6.

11. Srivastava MK, Sahoo RN, Ghotekar LH, Dutta S, Danabalan M, Dutta TK, et al. Risk factors associated with attempted suicide: A case control study. Indian J Psychiatry 2004;46:33-8.

12. Narang RL, Mishra BP, Nitesh M. Attempted suicide in Ludhiana. Indian J Psychiatry 2000;42:83-7.

13. Doganay Z, Sunter AT, Guz H, Ozkan A, Altintop L, Kati C, et al. Climatic and diurnal variation in suicide attempts in the ED. Am J Emerg Med 2003;21:271-5.

14. Shneidman ES. Current overview of suicide. In: Shneidman ES, editor. Suicidology; Contemporary Developments. New York: Grune and Stratton; 1976. p. 2-12.

15. Arun M, Mohanty MK, Nagesh KR, Palimar V. Geriatric poisoning fatalities: A Manipal perspective. Int J Medicoleg Update 2005;5:7-10.

16. Baby S, Haridas MP, Yesudas KF. Psychiatric diagnosis in attempted suicide. Calicut Med J 2006;4:2

17. Nagendra Gouda M, Rao SM. Factors related to attempted suicide in davanagere. Indian J Community Med 2008;33:15-8.

18. Kumar PN. Age and gender related analysis of psychosocial factors in attempted suicide. Indian J Psychiatry 1998;40:338-45.

19. Sharma RC. Attempted suicide in Himachal Pradesh. Indian J Psychiatry 1998;40:50-4.

20. Hawton K, Herringen V, editor. The International Handbook of Suicide and Attempted Suicide. John Willy and Sons, Ltd, The Atrium, Southern gate, Chicester, West Sussex P0198SQ, England. 2000.
21. Kumar CT, Chandrasekaran R. A study of psychosocial and clinical factors associated with adolescent suicide attempts. Indian J Psychiatry 2000;42:237-42.

22. Chandrasekaran R, Gnanaselane J. Predictors of repeat suicidal attempts after first-ever attempt: A two-year follow-up study. Hong Kong J Psychiatry 2008;18:131-5.

23. Logaraj M, Ethirajan N, Felix JW, Roseline FW. Suicidal attempts reported at a medical college hospital in Tamil Nadu. Indian $\mathrm{J}$ Community Med 2005;30:136-7.

24. Ponnudurai R, Jeyakar J, Saraswathy M. Attempted suicides in Madras. Indian J Psychiatry 1986;28:59-62.

25. Toomey Michele (2000), Women as Victims of Verbal Abuse, Liberation Psychology, [internet]. Available from: http://www.mtoomey.com/ womenasvictims.html (2000).

26. Pallis DJ, Barraclough BM, Levey AB, Jenkins JS, Sainsbury P. Estimating suicide risk among attempted suicides: I. The development of new clinical scales. Br J Psychiatry 1982;141:37-44.

27. Pillai A, Andrews T, Patel V. Violence, psychological distress and the risk of suicidal behaviour in young people in India. Int J Epidemiol 2009;38: 459-69.

28. Kaslow N, Thompson M, Meadows L, Chance S, Puett R, Hollins L, et al. Risk factors for suicide attempts among African American women. Depress Anxiety 2000;12:13-20.

29. Puducherry (Pondicherry) District: Census 2011 data [internet]. Available from: http://www.census2011.co.in/census/district/482 puducherry.html.

30. Pierce DW. Suicidal intent in self-injury. Br J Psychiatry 1977;130:377-85.

31. Singh G, Kaur D, Kaur H. Presumptive stressful life events scale (psles) A new stressful life events scale for use in India. Indian J Psychiatry 1984;26:107-14.

32. Goldberg DP, Williams P. A User's Guide to the General Health Questionnaire: Windsor: NFER-Nelson; 1988.

33. Ewing JA. Detecting alcoholism. The CAGE questionnaire. JAMA 1984;252:1905-7.

34. Viluppuram (Villupuram) District: Census 2011 data [internet]. Available from: http://www.census2011.co.in/census/district/27-viluppuram.html.

How to cite this article: Purushothaman $\mathrm{P}$, Premarajan KC, Sahu SK, Kattimani S. Risk factors and reporting status for attempted Suicide: A hospital-based study. Int J Med Public Health 2015;5:45-9. Source of Support: Received ICMR grant, Conflict of Interest: None declared. 